Geopolítica(s) Revista de estudios sobre espacio y poder ISSN: 2172-3958

\title{
Las relaciones económicas y políticas entre Estados Unidos de América y China a la luz del concepto de unipolarismo condicionado ${ }^{1}$
}

\author{
Patricio Narodowski ${ }^{2}$
}

Recibido: 19 de junio de 2017 / Aceptado: 27 de octubre de 2017

Resumen. El presente trabajo analiza el proceso de apertura y el consecuente ascenso chino como una estrategia de los EE UU para salir de la crisis del fordismo con impacto en términos de desindustrialización a favor de China y de los actuales balances comercial y financiero. Se analiza el impacto en el plano político y de las instituciones económicas y el poder que aún mantiene Estados Unidos y las limitaciones. En ese marco, se muestran las restricciones macroeconómicas de los EE UU en el contexto de un yuan competitivo. La conclusión a la que se llega es que "la sociedad" no resuelta con China, que es parte de la salida de la crisis de los 1970 y parece seguirá vigente en el futuro, limita los instrumentos a disposición de Estados Unidos para lograr el regreso de los eslabones industriales que hoy operan en Asia.

Palabras clave: geoeconomía; China; Estados Unidos; unipolarismo condicionado; crisis del fordismo.

\section{[en] USA-China Economic and Political Relations: Assessing the Concept of Conditional Unipolarism}

\begin{abstract}
The current work analyzes the process of opening and subsequent rise of China's economy as a U.S. strategy to overcome the crisis of Fordism. The impact has been notable as regards China's deindustrialization process and the current trade and financial balances. This impact is analyzed here on a political level and as pertains to the economic and power institutions in the U.S. The article addresses the macro-economic restrictions faced by the U.S. in the context of a competitive yuan. The main conclusion is that the prevalent "society" with China - part of the response to the 1970s crisis, which will presumably continue in the future - sets up limitations on the instruments available for the U.S. to achieve the return to the industrial areas operating today in Asia.
\end{abstract}

Keywords: geoeconomics; China; United States; conditioned unipolarism; crisis of Fordism.

\section{[pt] As relações econômicas e políticas entre Estados Unidos da América e China à luz do conceito de unipolarismo condicionado}

Resumo. O presente trabalho analisa o processo de abertura e a consequente ascensão chinesa como uma estratégia dos EUA para sair da crise do fordismo com impacto em termos de desindustrialização

1 Se agradece la contribución en la búsqueda bibliográfica y de datos de Matias Remes Lenicov y Mariano Kleiman.

2 Facultad de Humanidades y Ciencias de la Educación de la Universidad Nacional de La Plata (Argentina).

E-mail: p.narodowski@gmail.com 
a favor da China e dos atuais equilíbrios comercial e financeiro. Analise-se o impacto no plano político e no das instituições econômicas do poder que ainda mantém os Estados Unidos e suas limitações. Nesse contexto, descrevem-se as restrições macroeconômicas dos EUA diante de um yuan competitivo. A conclusão a que se chega é que "o acordo" não concluído com a China, que é parte da saída da crise dos anos 1970 e que talvez siga vigente no futuro, limita os instrumentos à disposição dos Estados Unidos para obter a renda dos enlaces industriais que hoje operam na Ásia. Palavras-chave: geoeconomia; China; Estados Unidos; unipolarismo condicionado; crise do fordismo.

Sumario. Introducción. 1. Crisis de los EE UU y hegemonía condicionada. Conceptos básicos. 2. Los vaivenes de los EE UU y su impacto en la globalización. 3. Los diferenciales de complejidad y de productividad que aún subsisten y "la sociedad chino-americana". 4. La hegemonía condicionada en las instituciones económicas internacionales. 5. Las dificultades para salir de la encerrona económica. Bibliografía.

Cómo citar: Narodowski, Patricio (2017) "Las relaciones económicas y políticas entre Estados Unidos de América y China a la luz del concepto de unipolarismo condicionado". Geopolítica(s). Revista de estudios sobre espacio y poder, vol. 8, núm. 2, 279-297.

\section{Introducción}

El presente trabajo tiene por objetivo analizar la relación de los EE UU con China en el marco del proceso más general de la globalización iniciado en los 1980 y que se consolida en los 1990. Se parte de un breve análisis del concepto de hegemonía como la consecuencia de la interacción recíproca entre variables económicas y político-militares para mostrar que el proceso de globalización - como aumento de flujos comerciales y financieros globales - fue una estrategia de los EE UU para salir de la crisis del fordismo iniciada en los 1970. De este modo, mantiene la hegemonía, pero a costa de un proceso de integración productiva con China, que significa a su vez una menor capacidad para imponer compromisos globales. Para describir este escenario retomamos el concepto de "unipolarismo condicionado", y el de centro-periferia, determinado por diferenciales de complejidad expuestos en trabajos anteriores (Apartado 1).

La clave está en el modo en que los EE UU salieron de la crisis de los 1970, dislocando el aparato productivo a escala global, a costa de producir el impulso de China, y generando los desbalances comerciales que ya hace unos 15 años presentan ambos en una suerte de extraña alianza colaborativa-competitiva. No debe olvidarse que mientras los EE UU tienen un excedente de consumo y gasto público que produce necesidades de endeudamiento, China tiene un saldo comercial positivo que le permite disponer de reservas. Esta relación ha contribuido a aumentar la deuda de EE UU. Los flujos comerciales, financieros y de Inversión Extranjera Directa (IED) explican buena parte del aumento de los flujos globales. También puede verse como esa estrategia es la causa de la crisis del 2008 y de la inestabilidad global actual (Apartado 2).

Esta alianza está fundada en las capacidades económicas relativas de ambos - abordadas en forma de diferenciales de complejidad-, se puede ver que los diferenciales aún subsisten a favor de EE UU y que la ventaja de China se basó en la explotación laboral y que, si bien ésta pierde competitividad salarial en su territo- 
rio, compensa con la IED en el resto de Asia, constituyéndose en coordinadora de los flujos de esa región (Apartado 3).

Este escenario de unipolarismo condicionado genera un nuevo equilibrio y eso se puede ver en el plano político y en las instituciones económicas. Se analizan en el Apartado 4 la incorporación de China en la OMC y el G20, el rol del FMI - sobre todo en la crisis del 2008- y las limitaciones de los instrumentos financieros basados en el euro o el yuan. Se observa que los EE UU han debido negociar más, pero conservan un fuerte poder de decisión global

En este contexto, se muestran las dificultades que tienen ambos para salir de la "encerrona económica" y así modificar el actual equilibrio; por un lado, la posibilidad de que la sociedad se mantenga y que China siga ejerciendo su soberanía monetaria para mantener un yuan competitivo pero sin lograr la complejidad de la economía norteamericana; por el otro, los límites de los EE UU — que se traducen en los debates - para implementar políticas tendentes a limitar los desequilibrios y que le permitan tener mayor autonomía.

Para afrontar la investigación, a los efectos de los debates más generales sobre el contexto mundial desde los 1970, se partió de los teóricos que hemos venido trabajando: Dos Santos, Lipietz, Wallerstein, Arrighi, Harvey, Petras o Tamames. Para el análisis del período de los 1980 en los EE UU se trabajó con Dos Santos y con los documentos de la Comisión Trilateral. Y se indagó en la bibliografía citada para lograr armar una secuencia de datos, aunque no es posible armar cuadros completos. Para el período más actual hemos incorporado la lectura de especialistas chinos y de otros países en revistas internacionales de economía y geopolítica.

En cuanto a la coyuntura americana y especialmente su relación con China, tanto por los datos como por las posiciones, se siguen permanentemente las publicaciones de los organismos internacionales: FMI, Banco Mundial, OMC, UNCTAD, United States Census, etc., así como los informes de los bancos centrales. También se consultan asiduamente informes bancarios como BBVA Research, y los medios comunes y financieros como Financial Times, New York Times, Los Angeles Times y la base de artículos de El País de España.

\section{Crisis de los EE UU y hegemonía condicionada. Conceptos básicos}

El concepto de hegemonía se ha venido discutiendo desde su surgimiento. Algunos autores desde un enfoque eminentemente político, otros como resultado de los procesos económicos, y naturalmente también hay una síntesis que intenta una interacción recíproca entre ambas direcciones de causalidad.

Los que analizan la hegemonía desde la economía política intentan esa interacción. Hemos rescatado en este sentido la diversidad de puntos de vista de Lipietz (1987), Wallerstein (1984, 2006), Harvey (2004), Arrighi (2001), Silver \& Slater (2003) y Petras (2003). Todos, menos Petras, sostienen que hay una pérdida de competitividad relativa en los EE UU y aceptan la tesis de su pérdida de poder y, por lo tanto, su menor capacidad para imponer alianzas, tanto económicas como políticas; eso se nota en las instituciones globales y en la coyuntura económica y político-militar. En todos ellos se ratifica la idea de la existencia de una división centro-periferia (Narodowski \& Remes Lenicov, 2012). 
En línea con los mencionados, nosotros seguimos con el concepto de "unipolarismo condicionado" (Narodowski \& Zapata, 2009). Se trata de un mundo en que los EE UU ha pasado por una crisis de la que no logra salir, que en ese proceso ha perdido competitividad a manos de China en un contexto de mutua interdependencia y en el que Alemania y Japón siguen siendo jugadores centrales. EE UU detenta un poder económico y político que aún le permite ser el árbitro, pero con ciertos límites.

Para fundamentar la hipótesis nos valdremos del concepto de complejidad, especialmente aplicado en relación al análisis del plano económico; el plano político, como se dijo en la introducción, será tocado levemente. Según el enfoque, en el centro predomina una especialización basada en la producción de bienes y servicios ubicados en eslabones intensivos en la ciencia y el conocimiento y en el diseño en un sentido amplio; sobresale un patrón de competencia vía diferenciación del producto (Narodowski \& Remes Lenicov, 2012). Hay además una semiperiferia fordista emergente, con cierta capacidad industrial basada en la escala (China, Rusia, la India), y una periferia, fundamentalmente proveedora de materias primas bajo un modelo de acumulación neotaylorista (Merino \& Narodowski, 2015).

\section{Los vaivenes de los EE UU y su impacto en la globalización}

Este escenario es consecuencia de la crisis de los 1970 y de la forma en que EE UU salió de ella, dislocando el aparato productivo a escala global y provocando el aumento de su balanza comercial negativa, de los flujos mundiales de comercio y el ascenso chino. Lo que queremos decir es que la crisis del fordismo tuvo su epicentro en los EE UU y fue este país, con sus políticas locales, el principal impulsor de la globalización. La política interna norteamericana, necesaria para salir de la crisis sin perder aún más, erigió el principio de multipolarismo que hoy limita, por ejemplo, los objetivos políticos y el tipo de alianza que quiere generar Trump y éste combate. Veremos a continuación cómo se da este proceso.

Desde la declaración de guerra en 1941 — y más aún desde la finalización de la misma-, los EE UU establecieron una estrategia que les permitió erigirse en una potencia global sin discusión. En el año 1944, en Bretton Woods, se forjó un régimen monetario internacional con el dólar como moneda internacional y los EE UU como centro financiero. Dos años más tarde se firma el acuerdo para promover el libre comercio mediante la reducción de los aranceles y la eliminación de las barreras al comercio internacional, Acuerdo General sobre Aranceles Aduaneros y Comercio (GATT, por sus siglas en inglés), antecedente de la actual Organización Mundial del Comercio (OMC). Ese mismo año se lanza el Programa Europeo de Recuperación (Plan Marshall), y también se firma la Employment Act, que incluía recortes de impuestos, gastos compensatorios, créditos fiscales (Wasem, 2013). Hasta la década de 1970 los sucesivos gobiernos siguen ese modelo, pero el ritmo de crecimiento declina, hasta transformarse en recesión en 1970 y en balanza comercial negativa en 1971 (United States Census, 2017a). Ese año se eliminó la libre conversión del dólar en oro. Luego de diversos vaivenes la economía que recibiría Reagan estaba sumida en la crisis: el nivel de actividad caía y la inflación cedía muy lentamente, a pesar del abandono de la política monetaria laxa, el déficit 
fiscal de 1980 ascendió al 2,6\% del PBI (May, 1993), pero con una balanza comercial equilibrada y un porcentaje de deuda baja en relación a la historia.

Los debates sobre la salida de la crisis de los EE UU crecían. Una de las posiciones fuertes era la de la Trilateral Commission, fundada en 1973 con el impulso de Rockefeller y Brzezinski. Se oponían al modo en que Nixon enfrentó la crisis, liberando el dólar y devaluando con un espíritu proteccionista, dentro del mismo carácter unilateral y guerrero que los había llevado a la derrota de Vietnam. Para resumir, diremos que con vaivenes y diversas intensidades, esa fue la estrategia de largo plazo.

La de Reagan no fue una presidencia exactamente orientada a la apertura comercial, aunque sí financieramente; sin embargo, de a poco iba notándose la presión hacia la globalización: el flujo mundial de comercio que en los inicios de los 1980 crecía al mismo ritmo que la producción (el primero al 2,9\% y el segundo al 3,2\%), entre 1985 y 1990 el comercio mundial empezó a crecer más (un 5,6\% contra el 4\% del PBI mundial) (Auboin et al., 2013). El flujo mundial total de IED se duplicó en la misma década hasta alcanzar los 200 billones de dólares (Zhan, 2010). El principal socio comercial era Japón.

China estaba "agazapada", aunque se preparaba para aprovechar la acumulación de factores productivos verificada desde la década de los 1950. La reforma de Deng Xiaoping en 1978 va en esa dirección: relajó notablemente los controles sobre el sector agrícola, y estimuló la emergencia de industrias a pequeña escala. En paralelo ese año se producía la devaluación del yuan, y así la moneda empezó a usarse como herramienta de incentivo a las exportaciones en un sistema de tipo de cambios múltiples que duró hasta 1993 (Xu, 2000; Zhu, 2012). En 1979 se firma el acuerdo con EE UU para establecer relaciones comerciales bilaterales sobre la base de la no discriminación, mutuo trato de nación más favorecida, y algunas cláusulas de derechos mutuos y resolución de controversias (Shijian, 2012). Ya en la era Reagan y con su venia, en 1983 China ocupó el antiguo puesto taiwanés dentro del FMI y el Banco Mundial, y solicitó la condición de observador dentro del GATT, y en 1986, de nuevo con el beneplácito de los EE UU, inicia un proceso de 15 años de duración hacia la adhesión a la OMC (Hufbauer \& Woollacott, 2012).

En la era Clinton los procesos se hicieron más vehementes. El dólar apreciado y el alza de tasas soportados, al menos en parte, debido al auge de la productividad (Tille, Stoffels \& Gorbachev, 2001). Los precios del petróleo bajos y la deflación en algunos países mantuvieron controlada la inflación a menos del $2 \%$ hasta el 2000, pero las entradas netas de capital pasaron del 1,5\% en 1995 al 4,2\% en 2000 (Council of Economic Advisers, 2006). Es el inicio de una nueva era de expansión financiera global en la que Estados Unidos es decididamente una economía que desahorra, un acreedor respecto al resto del mundo. Si con Reagan y Bush el endeudamiento empezó como consecuencia del déficit fiscal, con Clinton es debido a un clima de apertura, al diferencial entre generación de riqueza y consumo. Pero el proceso se estancó en 2001 (Carson, 2003).

Esto tiene los conocidos efectos en el boom del flujo mundial de comercio que creció de 1995 a 2000 un 7\% anual, una tasa nunca superada y el doble que la del PBI de 3,13\% (Auboin et al., 2013). No abundaremos en otros indicadores similares, pero sí diremos que la economía japonesa comenzó a agotarse y se produjo el auge de China. Ésta, en 1994, abolió el sistema de tipos de cambio doble y se creó una tarifa unificada vinculada al dólar estadounidense, depreciando el yuan en un 
44\%. En 1995 inicia un periodo de privatizaciones, permitiendo que muchas pequeñas empresas de propiedad estatal quebraran y fueran vendidas. Entre 1995 y 2001 la participación del sector estatal en el empleo total disminuyó del 17\% al $12 \%$. También se introdujeron formas de propiedad mixta dentro del sector estatal, y en algunas de gran escala se permitió la participación de accionistas, con una mayoría de acciones controladas por el Estado (Zhu, 2012). Hay otras políticas de liberalización bancaria y de incentivos impositivos. Esta política fue firmemente apoyada por Clinton con su "compromiso constructivo", reflejado fundamentalmente en el apoyo para el ingreso a la OMC (Yang, 2010), y promoviendo la inversión en China. En 1996 Clinton permitió que dos firmas estadounidenses se asociasen a China con el lanzamiento de satélites de telecomunicaciones, para algunos especialistas como devolución de aportes de campaña ${ }^{3}$. Hay otro tema central que influirá mucho, Hong Kong pasa a la soberanía china en 1997, luego de ser una colonia británica. Como consecuencia, China tuvo tasas de crecimiento de un promedio de más del 9,2\% anual entre 1990 y 2003 (Hernández Pedraza, 2005), se ubicó sexta en el PIB mundial, con una economía que alcanzaba los 1,41 trillones de dólares (Lau, 2004). Tampoco aquí abundaremos en los datos.

A los efectos de nuestra hipótesis es central decir que la balanza comercial de China y EE UU pasó a ser deficitaria para este último en 56.927 millones de dólares en 1998 y 68.677 millones en 1999 (United States Census, 2017b). China alcanzaba así el déficit del principal socio comercial, Japón. Estados Unidos era ya la principal fuente de inversión extranjera directa, 35\%, Hong Kong con un 10\% y Japón el 7\% (Sanger, 1999).

George W. Bush propuso e intentó la progresiva reducción de impuestos y el aumento del gasto, como una especie de vuelta a los 1980. La presión impositiva se redujo al mínimo histórico, $17 \%$. En cuanto al gasto, éste aumentó un $20 \%$ en cuatro años, hasta 2008 creció un 3,9\% anual promedio (Domitrovic, 2013). En 2004 ya había un déficit de 422.000 millones de dólares, el mayor desde el final de la Segunda Guerra Mundial (Ahmed, 2015). Todo validado por una política monetaria expansiva que mantenía el nivel de consumo pero que resultaría explosiva. Si bien hubo tímidos intentos de reducir los desequilibrios comerciales, Bush Jr. tuvo una actitud de amistad con China - tal vez debido al apoyo recibido el 11 de septiembre_-, el déficit logra sus niveles máximos en los años 2005 y 2006. China contribuía con su política de alineamiento al dólar, la política monetaria laxa, flexibilizando el sistema de empresas estatales y con una escasa liberalización de los servicios (Zhu, 2012). Como consecuencia, China se afianzó como la segunda potencia económica mundial según su PBI, que representó en 2010 el 9,3\% del producto mundial (el 46,8\% proviene del sector industrial). Las exportaciones aumentaron del 2000 al 2007 un 22\% contra el $18 \%$, de las importaciones, frente a un 5,5\% del aumento del comercio mundial (Quiroga, 2009).

Esto no significa que la relación comercial no haya sido accidentada: desde el 2001 ambos han realizado consultas en el Órgano de Solución de Diferencias de la OMC (Hufbauer \& Woollacott, 2012). EE UU generalmente por problemas de dumping, un tema recurrente es el de la discriminación a la entrada de autos norte-

Ver "Chinagate Is a Figment of Imaginations". Los Angeles Times [Puesto en línea el 21 de mayo de 1998. URL: <http://articles.latimes.com/1998/may/21/local/me-52008>. Consultado el 13 de abril de 2017]. 
americanos (WTO, 2014a); y China ha reclamado por barreras impuestas por el Departamento de Comercio de Estados Unidos (WTO, 2014b, 2015). En la presidencia de Obama se recrudece el problema del acero, y en los EE UU se aprueba la Ley de Recuperación y Reinversión en 2009, con el capítulo llamado "Buy American", que exige la compra local, en países del Nafta o que hayan firmado el Acuerdo sobre Contratación Pública (ACP) de la OMC de hierro, acero y otros productos en los proyectos fondeados por la ley y de vestimenta en organismos de seguridad (D’Elía, Fossati, Nava, Pérez Llana \& Galperín, 2016). Las promesas de cambios en la política cambiaria China no se cumplen. Chingo (2016) plantea que el enfriamiento de la economía china es mayor que el que muestran las cifras oficiales y hay una capacidad ociosa enorme, sobre todo en aluminio y acero, por eso siempre hay más problemas con los EE UU. Esto ocasiona el paro de algunas reformas que podrían bajar el superávit, como las que estimulan la producción de servicios básicos y financieros, fundamentalmente la reforma de la salud y también la esperada rebaja de la presión impositiva al consumo y el aumento de la presión sobre la inversión y las empresas estatales.

Producto de la crisis hay efectos en la globalización: la relación entre el comercio de mercancías y el PIB cayó abruptamente en 2009, pero se recuperó rápidamente en 2010-2011. En 2012-2014 disminuyó gradualmente, antes de caer significativamente en 2015, un 65\% superior al nivel de 2005. Esto da un incremento promedio anual similar al previo a la crisis (Escaith \& Maurer, 2016). En cuanto al flujo mundial total de IED, éstos aumentaron en un $38 \%$ en 2015 , su nivel más alto desde la crisis económica, pero siguen estando un $10 \%$ por debajo del pico de 2007. Todo en un contexto de moderado crecimiento del PIB mundial: $2,6 \%$ en 2015 (FMI, 2010c). Los precios de los commodities en el periodo 2010-2015 tuvieron una subida, con la excepción de la caída del precio del petróleo en 2015 del $45 \%$ (Escaith \& Maurer, 2016).

La participación de China en el PBI mundial a Paridad de Poder Adquisitivo (PPP) pasó del 17,5\% en 2008 al 16,4\% en 2014, pero China ocupa el primer lugar, superando ligeramente a la economía estadounidense. Ya la había desplazado en 2010 por el PBI industrial, aunque aún no lo logra si se mide en dólares corrientes. Es el mayor exportador y el segundo importador del mundo, tiene casi el 10\% del total de las exportaciones y el 7,9\% de las importaciones mundiales (Banco Mundial, 2013). También se mantiene la tendencia en cuanto a que China es el tercer mercado de exportación y la mayor fuente de importaciones de EE UU, y EE UU es el principal destino exportador de China, y Japón y Corea del Sur sus principales vendedores. Hay un saldo comercial negativo que ronda los 350 millones de dólares (Trillo, 2017). Hay que tener en cuenta que a mediados de los 1990 Hong Kong era comprador del $40 \%$ y vendedor del $20 \%$ de las importaciones.

\section{Los diferenciales de complejidad y de productividad que aún subsisten y "la sociedad chino-americana"}

En todo este proceso lo que se puede interpretar es que los vaivenes le sirvieron a los Estados Unidos para realizar una transición posfordista, que le permite seguir en un primer lugar en términos de complejidad económica, deslocalizando en Asia y México las partes más simples de sus complejos económicos. Esto le permite a 
EE UU asegurarse monopolios de rentas tecnológicas que se traducen en la cuenta de servicios reales, por eso, si bien ha perdido en 30 años el 2,5\% de la participación de las manufacturas en el PBI total, su balanza de cuenta corriente en esos servicios es siempre más positiva junto a la baja de servicios gubernamentales después de 2008 (Narodowski \& Remes Lenicov, 2014), generando un circulo virtuoso, ya que así logra sostenerse en la producción de bienes más sofisticados. Ya mostramos que dominan los eslabones industriales más dinámicos (Narodowski \& Remes Lenicov, 2014).

China, como contraparte, está aún especializada en bienes de complejidad media. Si bien China ha avanzado en el desarrollo de industrias estratégicas de mediana y alta complejidad, y se posiciona como uno de los países con mayor exportación de tecnología en porcentajes de exportaciones totales, aún no domina en los sectores de punta y tiene un alto porcentaje de su población laboral en sectores de baja complejidad o como ejército de reserva. Todavía en dicho sector China queda rezagada frente a los centros-nodos tradicionales y las Empresas Transnacionales (ETN) con origen en Estados Unidos, Europa, Japón e incluso Corea del Sur. Con el resto de los BRICS parece suceder lo mismo. Con este diagnóstico parecen coincidir diversos analistas (por ejemplo, Turzi, 2011). Pero sí se produjo en China un aumento relativo menor al esperado, pero importante en valores absolutos del consumo. Lo mismo ocurrió en México, pero en una escala muy inferior. Esto explica el grado de entrelazamiento de estas economías, sobre todo China: las empresas estadounidenses en EE UU abaratan sus costos con importaciones, las asentadas en China confían en su participación en ese mercado como un objetivo crítico para mantenerse competitivas a nivel mundial — a veces venden más que en su propio país- (Morrison, 2017).

La clave de la competencia china - y del aumento de las exportaciones industriales mexicanas - es el diferencial salarial por hora: una mano de obra barata debido al potencial y la sobreexplotación de la clase trabajadora asiática (HartLandsberg \& Burkett, 2010), que ha compensado con creces su desventaja en la productividad respecto de los países desarrollados. En los inicios del proceso, el salario mínimo era de 100 dólares en China y de 80 en México, contra 700 en los EE UU. Si bien los niveles salariales se han acercado, la productividad sigue siendo muy superior en los EE UU, claro que influenciada por los sectores donde tiene ventaja. Con el paso del tiempo, China hizo lo propio en el resto de Asia, coordinando estas economías con la japonesa, coreana y americana (UNCTAD, 2016), esto viene sucediendo desde 2011 (UNCTAD, 2015).

Esta división internacional del trabajo se ve en las balanzas sectoriales. Según datos procesados por Echenique Romero (2012), entre 2000 y 2007 la rama con un mayor saldo comercial negativo en EE UU fue la de computadoras y productos electrónicos, con el 26,14\% en 2007, seguido muy lejos por equipo eléctrico, aplicaciones y componentes, el cual detentó el 3,58\% del déficit manufacturero en 2000 y el 4,99\% en 2007. La rama que bajó fue equipo de transporte, del 23,1\% al $11,22 \%$. Textil e indumentaria está en alrededor del 12\%. Regionalmente, el déficit procede en gran medida de las relaciones comerciales con el Asia, que igual cayeron desde el NAFTA, sobre todo porque Japón paso del 58,7\% en 1992 al 27,67\% en 1995, aunque China pasó del $10 \%$ en 1990 al $40 \%$ en 2011 , le sigue la UE con el 12,84\%, Canadá 9,78\%, y México 7,23\%, es decir, el NAFTA superó a Europa. 
¿Cómo se explica esta especialización? Si damos cuenta del índice de ventaja comparativa revelada aportado por la misma autora, se ve que en industrias de baja complejidad, fundamentalmente textiles, prendas de vestir y calzado, China, Corea y Hong Kong, en ese orden, presentan una clara especialización desde 1995. En complejidad media, como partes y piezas, productos químicos y metales básicos y de ingeniería, pero de esas características, el liderazgo es de Japón y le sigue Corea del Sur. China aparece después. En alta tecnología, se distinguen Japón, Corea del Sur y Singapur, y luego recién China. Estados Unidos pierde con China en los sectores intensivos en mano de obra y con Japón en alta tecnología.

Como dijimos, la manera en que Estados Unidos logró mantener niveles altos de salario y consumo sin perjudicar su competitividad global fue dislocar el aparato productivo fuera de su territorio, pero esto generó un desequilibrio entre producción y consumo que explica su déficit comercial y el aumento del endeudamiento, mientras que la incapacidad de China de aumentar los salarios manteniendo su competitividad sobre esa base explica su superávit. Esto genera una alianza tácita entre la necesidad de financiamiento americano y el excedente chino que se traduce en la posibilidad de este país de invertir en activos del Tesoro norteamericano y también para financiar otros gobiernos, sobre todo de la periferia (Pozzo \& Zapata, 2011).

La crisis y la salida de ella es conocida, diremos aquí que no modifica de raíz este panorama y los desequilibrios se mantienen. Es interesante señalar que el Banco Central Chino acompañó la política norteamericana, incluso mantuvo su carrera hacia los bonos de ese origen. Sólo en 2009 planteó un plan bianual de estímulo a la infraestructura y seguridad social que buscaba compensar la declinante demanda norteamericana, pero esta política se frena rápidamente ante los temores de una burbuja interna.

\section{La hegemonía condicionada en las instituciones económicas internacionales}

China ha sido "cautelosa", con una estrategia de restricción deliberada en lo que respecta al aumento de la influencia económica y al uso de la fuerza (Domínguez, 2006). En paralelo, muestra la clara voluntad de jugar un rol político mayor. Tanto en el planteo de Deng Xiaoping como en los de Hu Jintao aparece la necesidad de ir al multilateralismo a partir de la participación activa de China en las organizaciones internacionales, tanto intergubernamentales como no gubernamentales, y en el desarrollo de un mecanismo de seguridad colectiva con el fin de reducir las medidas unilaterales adoptadas por los Estados Unidos (Barahona Lema, 2016; Chan, Lee \& Chan, 2008; Chin \& Thakur, 2010; Tamames, 2009; Abeles \& Kiper, 2010).

Si bien no nos ocuparemos específicamente de lo político-militar, antes de pasar a lo sucedido en el plano de las instituciones económicas, diremos que en este plano lo más importante ha sido la contienda en Irak, a la que EE UU va sin el apoyo de los principales países europeos ni de Rusia, afrontando un escenario difícil en lo político y en lo militar. Francia y Alemania, junto a China y Rusia, habían votado en contra en el Consejo de Seguridad de la ONU, reservándose una cierta independencia que antes de los 1970 no ostentaban. Claro que votan con Rusia y China, pero pugnan entre ellas por sus intereses en Europa del Este, en África y en Medio Oriente. EE UU se declara vencedor, pero instala en 2003 en Irak un go- 
bierno títere con el que se inicia un proceso lleno de avances y contramarchas que jamás conduce a un escenario estable. Al mismo tiempo, muestran una ambivalencia respecto al ISIS que concluye con la transformación de esta red en un enemigo inesperado y extraño al que no logra hacer frente incluso cuando éste ataca al aliado norteamericano que es Turquía. Luego vendrá la victoria parcial del gobierno de Siria y los acuerdos con Rusia para desmantelar el ISIS. Todos sus pasos parecen reflejar debilidad.

China de a poco ha comenzado a mostrar una posición político-militar cada vez más beligerante. Esto se sostiene con una estrategia que es percibida por EE UU como de profunda modernización militar, aunque muchos consideran que pasarán décadas antes de que las fuerzas armadas chinas puedan representar una amenaza para las estadounidenses. En este contexto, China acompaña a Rusia en las posiciones pro-sirias en la ONU. Los tres países han invertido en infraestructura en Siria y planifican el aumento de las relaciones, y su participación explica la victoria parcial actual.

Lo mismo sucede con la "Primavera Árabe", donde nadie es capaz de imponer un modelo de gobierno y en la que también se dirime la lucha por el petróleo. En Europa del Este, el caso de Ucrania podía verse como un triunfo, pero la incorporación a Rusia de Crimea lo compensa.

En América latina, China parecía haber avanzado, pero los cambios políticos parecen haber enfriado las relaciones, sobre todo con Brasil y Argentina. En el continente africano, China ha dado pasos importantes y hoy tiene un rol político inédito, sobre todo en Nigeria, Angola, Camerún y Sudán, aunque también en el norte de África. Los EE UU pugnaban por lo mismo, aunque sólo avanzaban en el área de Sudáfrica y sus vecinos. Ciertas opiniones valoran positivamente el código ético chino, que se basa en el dialogo sur-sur, sin condiciones, en base a proyectos de desarrollo, en este enfoque se dice que las materias primas se venden a un precio justo. Para otros, reproduce una forma de colonialismo en el sentido de un vínculo asimétrico con el fin de controlar los recursos naturales, además apoya gobiernos autoritarios en medio de conflictos militares, muchas veces de origen étnico.

Están los diversos conflictos del Pacífico y el Î́ndico (Jamarena \& Narodowski, 2015), en los que se entrecruzan buena parte de los aliados asiáticos de EE UU, principalmente Arabia Saudita, India y Japón, y la mayor parte de los problemas quedan sin resolver y hay una tensa calma. En el Mar del Este de China, al sur, a la altura del Golfo de Tonkín, está el conflicto con Vietnam y Taiwán, en medio de una gran integración económica. Las islas Paracel son reclamadas por los tres países, mientras que las islas Spratly son reclamadas en su totalidad por esos países y por Filipinas, Brunei, Indonesia y Malasia. China y Filipinas acordaron en 2003 estudios conjuntos de exploración en el Mar del Sur de China, lo que irritó a Vietnam. PetroChina y PetroVietnam realizan prospecciones en aguas disputadas. Hanoy pidió a China que interrumpiese sus labores de exploración en el golfo de Tonkín. Hillary Clinton planteó el tema y obtuvo el rechazo chino. La controversia por Taiwán está cruzada por otros factores, fundamentalmente que para China hay una sola China y Taiwán quiere profundizar su independencia en el marco de su alianza con los EE UU.

Por último, al norte, con Japón tiene dos asuntos: los campos de gas offshore de Chun Xiao, Dunquiao y Tianwaitan, muy cerca de la mediana entre China y Japón y las reservas de petróleo en los alrededores de las islas Senkaku, muy cerca de 
Taiwán (que los chinos llaman Diaoyu) ocupadas por Japón y reclamadas por China. Se disputan los derechos de perforación entre Shanghái y el archipiélago de Okinawa. China rechaza la propuesta de desarrollar conjuntamente cuatro yacimientos de gas natural y de crudo.

Este conflicto territorial esconde uno muy profundo: históricamente China y Japón han competido por la supremacía en Asia. En Japón hay un debate similar al de los EE UU, en el sentido de que China podría "destronarlo" en las próximas décadas de su posición como potencia económica en Asia, atributo al cual agregaría un renovado poder militar, sobre el cual los japoneses están alertando (Abad, 2011).

Y, además, resta el caso de Corea del Norte, que siempre representa una amenaza para los EE UU y la otra Corea, y China parece ponerse del lado de Corea del Norte, aunque con una cierta distancia. Esto se vio en el hundimiento de la corbeta surcoreana Cheonan en el Mar Amarillo, y cuando Corea del Norte decidió responder a los ejercicios militares de Corea del Sur en 2010.

Parece, en todo caso, un escenario mucho más equilibrado que el de los primeros años 1990. Trump ha prometido resolver definitivamente algunos de estos conflictos, pero en cada oportunidad en que intenta una acción global, debe volver al equilibrio anterior.

En lo que hace a las instituciones económicas, la creación de la UE, el auge de los tratados comerciales y el nuevo rol de China en esa puja, así como la incorporación de China en la $\mathrm{OMC}$, son ejemplos de un cierto multilateralismo. El fracaso del G20, los pocos cambios en el accionar del FMI y las limitaciones que sufrieron los instrumentos financieros que debían catapultar al yuan en el mercado internacional parecen ir en sentido contrario. Pero la alianza estratégica entre ambos países explica por qué China conserva la soberanía cambiaria y sigue devaluando según sus propios objetivos y no los de ciertas presiones internacionales.

En orden cronológico hay que destacar el surgimiento del euro el 1 de enero de 1999 como unidad de cuenta, que finalmente entró en circulación en 2002 con 11 países y hoy en día abarca a 19. Mientras el EE UU de Reagan, en paralelo, proponía un acuerdo que México rechazó. Recién en 1994 se firmó el Tratado de Libre Comercio de América del Norte (TLCAN) que integró a los ya socios EE UU y Canadá con el vecino México. El bloque tiene una importancia similar a la de Europa en el comercio global, ya que representa el $48 \%$ del mismo. Se vende a si mismo un $32 \%$, mucho menos que Europa, y está más abierto sobre todo con Asia.

Pero, además, EE UU se lanzó a la caza de tratados como una forma de generar espacios de comercio bilaterales impensables en la posguerra. Los mismos han estado sujetos a la aprobación de la Trade Promotion Authority (TPA) que establece reglas especiales en relación a productos agroalimentarios protegidos, como la carne bovina, el tabaco, algodón, maní, azúcar y lácteos, casi el $40 \%$ de las posiciones arancelarias. Dichas aprobaciones pasan por los durísimos Comités Agrícolas de la Cámara y del Senado. En la actualidad, EE UU tiene tratados de libre comercio (TLC) con 20 países. Casi el 50\% del comercio se realiza dentro de un tratado. Desde 2009, las exportaciones por esta vía se han incrementado un $64 \%$, contra el $45 \%$ en el resto de los destinos (Fraser Chase, 2015).

A su vez, como veremos, integra el Asia Pacific Economic Cooperation (APEC), y se estaba negociando la Asociación Transpacífico (TPP) con Singapur, Vietnam, Brunéi y posiblemente Filipinas, sumando a éstos a la ya exclusiva relación de EE UU con Taiwán, India y Japón. En el primer caso se intentaba sustraer a 
China a relación con estos países, junto a los miembros latinoamericanos. Sin embargo, muchos creen que iba a ser un modo para China de triangular hacia los EE UU. Con fines similares se firmó el Acuerdo del Pacífico (AP), como un modo de competir con el MERCOSUR una vez fracasado el ALCA y también fortificar la zona contra el siempre activo comercio de Chile y Perú con China.

China fue por un camino similar, firmó un TLC con ASEAN-6 y así se redujeron los aranceles de siete mil productos. Y hay un trato flexible con Camboya, Laos, Myanmar y Vietnam (Odarda, 2008). Este grupo fue central para la descentralización productiva de Japón y ahora lo es para China, que ha incrementado un $20 \%$ anual su comercio con la zona en los últimos años. Incluso luego de la crisis del 2008 China dio un préstamo a estos países en el marco del Fondo de Inversión de Cooperación de China-ASEAN por el cual mostró querer convertirse en una especie de instrumento anticíclico en estas economías. El TPP debía interferir en esta dinámica, pero también se corría el riesgo de fortalecerla.

En Asia Oriental, China ha querido avanzar, pero la propuesta ha sido rechazada por Japón. En paralelo, China firmaba o ratificaba Acuerdos de Cooperación Económica Más Estrecha (CEPA) con Hong Kong y Macao y firmaba TLCs con Pakistán, Nueva Zelanda, Singapur, Chile, Perú y Costa Rica. Se debe mencionar además la firma de acuerdos con el Consejo de Cooperación del Golfo (Arabia Saudí, Kuwait, Qatar, Omán, Bahrein y los Emiratos Árabes Unidos), aunque en estos casos no pudo firmar TLC. Intenta un acuerdo con la Unión Aduanera Sudafricana (Sudáfrica, Botswana, Namibia, Lesotho y Swazilandia), que no se consolida. Como se ve, los países intentan pasar por ambas ventanillas, y los EE UU - vía Japón, Sudáfrica o Arabia Saudita - tratan de impedir esa estrategia. El aumento de la participación del comercio chino en cada país es una muestra de lo limitado de la estrategia. Con Rusia, Kirguistán, Kazajistán, Tayikistan y Uzbekistán formaron la Organización de Cooperación de Shangai (OCS).

Al mismo tiempo, China se incorpora luego de un proceso largo, a la OMC, noticia saludada en ese momento por los gobiernos involucrados y los organismos internacionales (Adhikari \& Yang, 2002). La estrategia se volvió un boomerang, EE UU y Europa comenzaron a realizar presentaciones contra China por el proteccionismo. La OMC iba perdiendo peso por los tratados bilaterales o multilaterales mencionados y se transformaba en el lugar de la solución de controversias entre China y los EE UU. Uno de los temas más complejos es el acero; otro tema recurrente es el de la discriminación a la entrada de autos norteamericanos. El excelente trabajo de D’Elía, Fossati, Nava, Pérez Llana \& Galperín (2016) muestra el nivel de conflictividad mencionado: en los trámites China aparece más cuestionada y, como corolario, en la OMC Estados Unidos y la Unión Europea (UE) se oponen abiertamente a concederle a China el estatus de "economía de mercado". La estrategia de incorporar a China al capitalismo, parece controvertida, Trump lo sabe.

Y también se esperaba que la creación del G20, un foro deliberativo, pero no decisorio surgido a iniciativa del G7 en 1999, reflejara la nueva multilateralidad, pero si se analizan las cumbres, las mismas han sido un fracaso por la negativa de los EE UU a regular el sistema financiero (Morales Fajardo \& Hurtado Jaramillo, 2009). Del mismo modo, no hubo nueva arquitectura internacional y el FMI parece haber sufrido escasas transformaciones, como si este multilateralismo no lo hubiera alcanzado; durante los 2000 no aparecen en los documentos institucionales críticas directas a la política expansiva de los EE UU, a pesar de que esas políticas deter- 
minaron los desequilibrios de la década (Guzmán \& Vargas, 2016). En documentos oficiales el FMI (2010a, 2010b) se menciona la baja en la tasa de interés real y la volatilidad, que derivaron en riesgo sistémico y se sumaron al fracaso en políticas prudentes, junto al optimismo derivado de un largo período de alto crecimiento. En relación a China, coherentes con el planteo americano que tampoco denunció demasiado, sólo hablan tímidamente de desajustes cambiarios; a fines de 2015 incluyó al yuan en su canasta de monedas de referencia como resultado de supuestas mejoras del mercado cambiario. Propone el ajuste y más medidas de prudencia. El programa general de ajuste fiscal, no exigido a los EE UU en los 2000, no sufrió variaciones, esto queda claro en las recomendaciones del organismo en Irlanda e Islandia y Letonia, y desde 2010 en cooperación con el Banco Central Europeo sobre todo en Grecia, Portugal y España.

Mientras tanto, ha habido otros proyectos de instituciones financieras alternativas que aún no logran consolidarse, sobre todo alrededor de la fortaleza del yuan. Un primer intento de generar una institución financiera ajena al dólar parece ser la creación de un Consejo Interbancario de la ya mencionada OCS para la futura financiación de proyectos, que por su magnitud iban a tener gran trascendencia. El Consejo hoy por hoy no existe y ya vimos que la OCS sufrió diversos vaivenes. Tampoco funcionó esto en el marco de los BRICS. Con América Latina se propuso el Fondo de Cooperación, Inversión y Finanzas y la apertura del Banco de Desarrollo de China en diversos países de la región, pero esos proyectos se estancaron. Sólo prosperaron los swaps bilaterales, que luego también se interrumpieron. En 2014 se iniciaron de nuevo tratativas aún no concluidas para un sistema de intercambio con Rusia sin pasar por el dólar, que sólo derivaron en el aumento de las reservas rusas en dólar de Hong-Kong.

Los mencionados elementos de multilateralismo mencionados parecen perder peso en la crisis del 2008, ya que la misma se generó en - y fue enfrentada porEE UU. La sucesión de hechos está descripta en Narodowski, Pozzo \& Zapata (2008), allí se ve además como China trabajó en conjunto para sostener el modelo actual y, cómo vimos, los intentos de aumentar el consumo interno para lograr una cierta independencia chocaron con los propios límites del modelo. Más en general, si hasta la crisis del 2008 un número creciente de bancos centrales había ido cambiando sus reservas de dólares a euros, generando más dudas acerca de la capacidad actual del dólar de cumplir el rol de ancla debido a la debilidad estructural que acabamos de mostrar, debido a la nueva división internacional del trabajo que además repercute en su propia dinámica económica y política interna (Elwell, 2008; Lin \& Dailami, 2011), la crisis del 2008 mostró que las restantes divisas que podían disputarle el reinado al dólar, aún no se encontraban en condiciones de hacerlo (Saccomanni, 2010).

\section{Las dificultades para salir de la encerrona económica}

Lo que acabamos de ver muestra que durante el periodo que va de la crisis del petróleo hasta los 2000, el socio comercial fundamental y al mismo tiempo el país que encarnaba la competencia dentro del capitalismo era Japón, que iba ganando en complejidad mientras dominaba el pasaje a la "era de la electrónica" y se transformaba en exportador neto. EE UU, de todos modos, conservaba una cuenta corriente 
equilibrada. Los EE UU comenzaron a plantear una estrategia que — vía aumento del déficit público, vía el déficit comercial o, como ahora, ambos - lo ha llevado a ser deficitario en la cuenta corriente, fenómeno que se va profundizando con el paso del tiempo hasta alcanzar un piso superior al $-2 \%$. El peso de los intereses ha neutralizado el aumento positivo de los servicios tecnológicos. Este proceso es el que ha producido el ascenso chino y debe decirse que se dio, aunque con distintas intensidades, sin distinción del color político de los gobiernos.

Es claro que el problema de los EE UU es la cuenta comercial y la cuenta corriente, y para resolverlos la única opción es lograr una participación relativa mayor de la inversión y/o las exportaciones, y menor del consumo y/o el gasto público y las importaciones. Sólo eso podría permitirle volver a una independencia comercial que le abra las puertas a recobrar su hegemonía absoluta. El problema de China es el mismo, pero a la inversa: sostener la inversión — cosa que viene logrando-, aumentar el consumo - proceso que se dio muy lentamente y se frenó prácticamente en 2009- y bajar el gasto público y/o las exportaciones, procesos que no se han dado en absoluto. Sólo así podría lograr esa misma independencia de los EE UU. El caso de México sería similar, pero en el corto plazo no parece posible que lo logre (Sirkin, 2014). La solución ha seguido siendo la guerra de divisas; la devaluación de 2015 es una prueba de que esta política continúa y el gran perdedor es el consumo. La conclusión a la que se llega es que primará el manejo cambiario, como hasta ahora.

¿Y los EE UU? Obama comprendía este diagnóstico sobre China y actuó en consecuencia. El objetivo fue mejorar la cuenta corriente vía un menor impulso fiscal, como lo hiciera Clinton, y llegó a un -2,1\%. En el largo plazo junto a una mayor disciplina fiscal se confiaba en mantener la economía abierta, y profundizar un fenómeno del que desde 2010 ya se venía hablando en los EE UU: la reindustrialización, vía un aumento paulatino pero genuino de la competitividad americana, por la vía de la inversión, la innovación y para lo cual la baja de los precios del petróleo - que en Narodowski \& Remes Lenicov (2015) hemos mostrado como una política deliberada - representaba una oportunidad importante. Esta estrategia es compatible con la globalización reinante, pero el resultado que puede esperarse es el de tasas de crecimiento bajas, el regreso a un escenario pre-Reagan pero con una economía abierta. El problema fue que los datos de 2016 no fueron positivos: con un déficit de cuenta corriente levemente en alza $(-2,5 \%)$ y un déficit fiscal en tímida baja $(-3,2 \%)$, el crecimiento fue sólo del 1,6\%.

Trump en cambio plantea que hay elementos similares a la economía del 1981 y su respuesta parece similar a la de Reagan: los indicadores comunes son la exigua tasa de crecimiento, una alta desocupación, pero inferior a la de aquella época, el contexto de alza de tasas que ya se esperaba en el fin de la era Obama - debido a que la misma repuntó en diciembre de 2016, cuando el IPC se situó en el 2,1\%-, pone en riesgo el nivel de actividad y va a apreciar el dólar. Las diferencias estriban en que el impulso del consumo y el gasto son mayores y sobre todo el déficit en la cuenta corriente, que parece mantenerse ya que China no parece dispuesta a apreciar el yuan. La respuesta es similar a la de Reagan porque la apuesta es bajar costos aumentando el impulso fiscal neto y la deuda, disminuyendo el consumo y atrayendo la inversión privada para aumentar la productividad: por eso el eje es reducir la presión impositiva y el gasto social y elevar el gasto en infraestructura, 
también aligerar la legislación ambiental. El modelo requiere de una política monetaria restrictiva que ya ha comenzado.

Finalmente - consciente de que las mencionadas mejoras en la productividad serán pobres en el corto y mediano plazo-, propone volver a los niveles de protección anteriores a los 1990, previos a la globalización, defendiendo de la importación a los sectores que tienen la competencia de China y México, para reimpulsar fundamentalmente la cadena sider-metalmecánica-automotriz a fin de hacer volver la producción de eslabones industriales que se perdieron y así reconstruir el poderío industrial americano.

El problema de fondo es el potencial aumento de los costos internos de los insumos, porque los eslabones en que compite China son ineficientes en los EE UU $y$, por ende, la cuestión es el nivel inflacionario. Para enfrentar este problema debe elevar los subsidios, presionando sobre las cuentas públicas y de allí a la cuenta corriente, una parte de la mejora en la balanza comercial se perderá por esta vía, la diferencia será escueta y buena parte de las ganancias de la protección se perderían con la apreciación del dólar. El empleo difícilmente se beneficiará en el largo plazo. La solución sería que se ganase en productividad y se pudiese bajar la protección, pero eso no es seguro, y además en este escenario China puede tomar represalias.

Todos los analistas coinciden en que China seguirá pugnando y defendiéndose en los organismos internacionales y usando su soberanía monetaria para mantener un yuan competitivo. La alianza entre ambos probablemente impida a EE UU castigarla. La sociedad no resuelta con China lo limita, incluso en sectores claves como el metalmecánico. Pero esta contradictoria alianza seguirá vigente por varios años.

\section{Bibliografía}

Abad G (2011) Las nuevas líneas fundamentales del Programa de Defensa Nacional de Japón y las relaciones sino-japonesas. ARI, Real Instituto Elcano, Madrid. [Puesto en línea el 07 de febrero de 2011. URL: $<$ www.realinstitutoelcano.org/wps/wcm/connect/1ff6a80045b4275199e2df5e7489e10f/ ARI212011_Abad_Programa_Nacional_Defensa_Japon_relaciones_sino_japonesas.pdf?MOD $=$ AJPERES\&CACHEID $=1 \mathrm{ff} 6 \mathrm{a} 80045 \mathrm{~b} 4275199 \mathrm{e} 2 \mathrm{df5e} 7489 \mathrm{e} 10 \mathrm{f}>$. Consultado el $15 \mathrm{de}$ septiembre de 2017].

Abeles, Martin \& Kiper, Esteban (2010) "El G20 y el rol de la Argentina". Aeda (Serie Aportes, núm. 2). Buenos Aires: Fundación Friedrich Ebert [URL: $<$ http://library.fes.de/pdf-files/bueros/argentinien/07653.pdf>. Consultado el 12 de febrero de 2017].

Adhikari, Ramesh \& Yang, Yongzheng (2002) “¿Qué significará el ingreso en la OMC para China y sus socios comerciales?”. Finanzas y desarrollo, vol. 39, 22-25.

Ahmed, Alouani (2015) "Inflation and Growth in the USA, From Eisenhower to G. W. Bush: A Descriptive Study". International Journal of Economics, Finance and Management, vol. 4, núm. 2, 61-67. 
Arrighi, Giovanni (2001) Caos y Orden en el Sistema-Mundo Moderno. Madrid: Ediciones Akal.

Auboin, Marc et al. (2013) World Trade Report 2013. Factors Shaping the Future of World Trade. Geneva: World Trade Organization.

Banco Mundial (2013) China 2030. Building a Modern, Harmonious, and Creative Society. Washington D. C.: The World Bank.

Barahona Lema, Verónica (2016) "La relevancia de China en la conformación de un nuevo orden geopolítico y económico mundial”. AFESE, vol. 62, núm. 62, 66-81.

Carson, Carol (2003) Foreign Direct Investment Trends and Statistics. S/1: International Monetary Fund.

Chan, Lai-Ha; Lee, Pak K. \& Chan, Gerald (2008) "Rethinking global governance: a China model in the making?". Contemporary Politics, vol. 14, num. 1, 3-19.

Chin, Gregory \& Thakur, Ramesh (2010) "Will China Change the Rules of Global Order?". The Washington Quarterly, vol. 33, núm. 4, 119-138.

Chingo, Juan (2016) “¿Nueva crisis de la deuda como en 1980 o una crisis asiática ampliada?" Diario La Izquierda [Puesto en línea el 8 de enero de 2016. URL: $<$ http://laizquierdadiario.com/Nueva-crisis-de-la-deuda-como-en-1980-o-una-crisisasiatica-ampliada $>$. Consultado el 20 de abril de 2017].

Council of Economic Advisers (2006) Economic Report of the President. Washington D. C.: U. S. Government.

D’Elía, Carlos; Fossati, Verónica; Nava, Juan; Pérez Llana, Cecilia \& Galperín, Carlos (2011) "China: las medidas de respuesta a la crisis económica internacional y su lugar en el comercio mundial”. CEI, núm. 19, 101-122.

Domínguez, Jorge (2006) "China's relations with Latin America: shared gains, asymmetric hopes”. Inter-American Dialogue [Puesto en línea en junio de 2006. URL: $<$ http://www.offnews.info/downloads/china-latam.pdf $>$. Consultado el 12 de marzo de 2017].

Domitrovic, Brian (2013) “Obama's Economy Is Worse Than Bush's, By Obama's Own Numbers". Forbes [Puesto en línea el 1 de octubre de 2013. URL: $<$ https://www.forbes.com/sites/briandomitrovic/2013/10/01/obamas-economy-is-worsethan-bushs-by-obamas-own-numbers/\#58e06fa79d7a>. Consultado el 16 de marzo de 2017].

Echenique Romero, Ximena (2012) "El déficit comercial de Estados Unidos frente a la entrada de China a su mercado". Análisis, núm. 2, 63-88.

Elwell, Craig (2008) Dollar Crisis: Prospect and Implications. S/1: CRS Report for Congress.

Escaith, Hubert \& Maurer, Andreas (2016) World Trade Statistical Review. S/l: World Trade Organization.

FMI (2010a) How Did Emerging Markets Cope in the Crisis? Washington D. C.: IMF Policy Paper.

FMI (2010b) Perspectivas de la economía mundial al día: actualización de las proyecciones centrales. Washington, D.C.: IMF Policy Paper.

FMI (2010c) World Economic Outlook Update: Restoring Confidence without Harming Recovery. Washington, D.C.: IMF Policy Paper.

Fraser Chase, Kim (2015) "La balanza comercial de EE.UU.: entonces y ahora". BBVAResearch. Observatorio Económico EEUU, 8 de abril de 2015. 
Guzman, David \& Vargas, Stephany (2016) "FMI, brazo financiero de EE UU". Revista PUCE, núm.103, 299-311.

Hart-Landsberg, Martin \& Burkett, Paul (2005) China and Socialism: Market Reforms and Class Struggle. Nueva York: Monthly Review Press.

Harvey, David (2004) El Nuevo Imperialismo. Madrid: Ediciones Akal.

Hernández Pedraza, Gladys (2005) "Evolución actual y perspectivas de las relaciones China-ASEAN”, en CLACSO (eds.) La economía mundial y América Latina. Tendencias, problemas y desafios. Buenos Aires: CLACSO, 107-138.

Hufbauer, Gary \& Woollacott, Jared (2012) "Trade Disputes Between China and the United States: Growing Pains so Far, Worse Ahead?". European Yearbook of International Economic Law, vol. 3, 31-40.

Jaimarena, Rocio \& Narodowski, Patricio (2015) "La geopolítica de la complejidad. El caso de las disputas de China en el mar de la China". Ponencia presentada en IX Jornadas de Economía Crítica, Sociedad de Economía Crítica, Rio Cuarto, Córdoba (Argentina).

Lau, Lawrence (2004) China in the Global Economy. Stanford: Stanford University.

Lin, Justin \& Dailami, Mansoor (2011) "Preparing for a multipolar world economy" [Puesto en línea el 19 de junio de 2011. URL: $<$ http://english.aljazeera.net/indepth/opinion/2011/06/2011618134516152339.html $>$. Consultado el 20 de abril de 2017].

Lipietz, Alain (1987) Miragens e Milagres. Problemas da industrialização do Terceiro Mundo. São Paulo: Nobel.

May, Ann (1993) Fiscal Policy, Monetary Policy, and the Carter Presidency. Nebraska: Economics Department Faculty Publications.

Merino, Gabriel \& Narodowski Patricio (2015) "La agudización de las tensiones globales. Análisis de la crisis del orden unipolar y los conflictos geoestratégicos desde una perspectiva centro-periferia". Estudios Socioterritoriales. Revista de Geografia, núm. 18, 81-99.

Morales Fajardo, María \& Hurtado Jaramillo, Annel (2009) "Los acuerdos del G8 y G20: ¿Remedios o paliativos para salir de la crisis económica?”. Economía Actual: Revista de Análisis de Coyuntura Económica, año 2, núm. 4, 25-28.

Morrison, Wayne (2017) China-U.S. Trade Issues. Washington D. C.: Congressional Research Service.

Narodowski, Patricio; Pozzo, Horacio \& Zapata, Federico (2008) La crisis económica internacional del 2008, el impacto en la Argentina y en la Provincia de Buenos Aires. Buenos Aires: Ministerio de Economía y Producción de la Provincia de Buenos Aires.

Narodowski, Patricio \& Remes Lenicov, Matías (2012) Geografía Económica Mundial. Un enfoque centro-periferia. Moreno (Buenos Aires): Universidad Nacional de Moreno.

Narodowski, Patricio \& Remes Lenicov, Matías (2014) Geografía Económica Mundial. Un enfoque centro-periferia. Vol. 2. Las cadenas globales de valor. Moreno (Buenos Aires): Universidad Nacional de Moreno.

Narodowski, Patricio \& Zapata, Federico (2009) “América Latina y el ascenso Chino. Un ejercicio de geopolítica periférica y realismo estratégico". Ponencia presentada en EGAL 2009, Montevideo (Uruguay).

Odarda, Omar (2008) "Estado de Situación de las Negociaciones de Libre Comercio de China”. Secretaría de Agricultura, Ganadería, Pesca y Alimentos. Conserjería Agrícola. Embajada Argentina en la República Popular China. 
Petras, James (2003) “Construcción imperial y dominación” [Puesto en línea el 6 de agosto de 2003. URL: <https://www.rebelion.org/hemeroteca/petras/030806petras.htm>. Consultado el 28 de marzo de 2017].

Pozzo, Horacio \& Zapata, Federico (2011) La crisis económica internacional y los nuevos escenarios post crisis. Buenos Aires: Ministerio de Economía de la Provincia de Buenos Aires.

Quiroga, Gloria (2009) "China, 30 años de crecimiento económico”. Anuario jurídico y económico esculiarénse, vol. XLII, 463-480.

Saccomanni, Fabrizio (2010) "The global crisis and the future of the international monetary system”. Conferencia invitada del Director General del Banco de Italia en la Chinese Academy of Social Sciences, Beijing, 15 April 2010.

Sanger, David (1999) "Trade deficit hit new high in 1998". The New York Times [Puesto en línea el 20 de febrero de $1999 . \quad$ URL: $<$ http://www.nytimes.com/1999/02/20/business/trade-deficit-hit-new-high-in1998.html>. Consultado el 15 de abril de 2017].

Shijian, Zhou (2012) "China-U.S. economic relations: accords and discords" [Puesto en línea el 27 de febrero de 2012. URL: <http://www.china.org.cn/opinion/201202/27/content_24744473.htm>. Consultado el 20 de abril de 2017].

Silver, B. J. \& Slater, E. (2003) "The social origins of world hegemonies", en G. Arrighi \& B. J. Silver (eds.) Chaos and Governance in the Modern World System. Minneapolis: University of Minnesota Press, 151-191.

Sirkin, H (2014) "China vs. the U.S.: It's Just as Cheap to Make Goods in the USA" [Puesto en línea el 25 de abril de 2014. URL: <https:/www.bloomberg.com/news/articles/201404-25/china-vs-dot-the-u-dot-s-dot-its-just-as-cheap-to-make-goods-in-the-usa $>$. Consultado el 20 de abril de 2017].

Tamames, Ramón (2009) "The future world financial framework: european and asian impulses in favour of a global currency". Conferencia invitada, Canon Foundation in Eu-

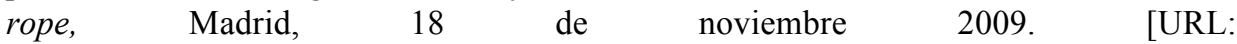
$<$ http://register.canonfoundation.org/_images/2009_lecture/Madrid_18.11.09_Canon_e nglish_pdf $>$. Consultado el 12 de febrero de 2017].

Tille, Cedric; Stoffels, Nicolas \& Gorbachev, Olga (2001) "To What Extent Does Productivity Drive the Dollar?". Current Issues in Economics and Finance, vol.7, núm 8, 1-6.

Trillo, Manuel (2017) "La desequilibrada relación comercial entre China y Estados Unidos". $A B C$ [Puesto en línea el 25 de enero de 2017. URL: $<$ http://www.abc.es/internacional/abci-desequilibrada-relacion-comercial-entre-china-yestados-unidos-201701250334_noticia.html>. Consultado el 20 de marzo de 2017].

Turzi, Mariano (2011) Mundo BRICS. Las potencias emergentes. Buenos Aires: Capital Intelectual.

United States Census (2017a) "U.S. Trade in Goods and Services - Balance of Payments (BOP) Basis, 1960-2016”. [Puesto en línea el 2 de junio de 2017. URL: $<$ https://www.census.gov/foreign-trade/statistics/historical/gands.pdf $>$. Consultado el 30 de marzo de 2017].

United States Census (2017b) "Trade in Goods with China" [Puesto en línea s/f. URL: $<$ https://www.census.gov/foreign-trade/balance/c5700.html\#1985>. Consultado el 30 de marzo de 2017].

UNCTAD (2015) World Investment Report. Reforming International Investment Governance. S/l: UNCTAD. 
UNCTAD (2016) Informe sobre las inversiones en el mundo 2016. Nacionalidad de los inversores: retos para la formulación de políticas. Nueva York y Ginebra: UNCTAD.

Wallerstein, Immanuel (1984) "Long waves as Capitalism Process". Review, vol. 7, núm 4, 559-575.

Wallerstein, Immanuel (2006) Capitalismo storico e civiltá capitalistica. Italia: Asterios Editore SRL.

Wasem, Ruth (2013) "The Employment Act in Historical Perspective", en Tackling Unemployment: The Legislative Dynamics of the Employment Act of 1946. Kalamazoo, MI: W.E. Upjohn Institute for Employment Research Upjohn Institute for Employment Research, 1-10.

WTO (2014a) "United States - Countervailing and Anti-dumping Measures on Certain Products from China" [Puesto en línea s/f. URL: $<$ https://www.wto.org/english/tratop_e/dispu_e/cases_e/ds449_e.htm>. Consultado el 16 de marzo de 2017].

WTO (2014b) "China - Anti-Dumping and Countervailing Duties on Certain Automobiles from the United States". [Puesto en línea s/f. URL: $<$ https://www.wto.org/english/tratop_e/dispu_e/cases_e/ds440_e.htm>. Consultado el 16 de marzo de 2017].

WTO (2015) International Trade Statistics 2015. S/1: World Trade Organization.

$\mathrm{Xu}$, Yingfeng (2000) "China's exchange rate policy". China Economic Review, vol. 11, núm. 3, 262-277.

Yang, E. (2010) "EEUU y China, compitiendo en la razón y en la fuerza". [URL: $<$ http://www.politicachina.org/imxd/noticias/doc/1274409361EEUU_y_China_compitie ndo_en_la_razon_y_en_la_fuerza.pdf $>$. Consultado el 12 de marzo de 2017].

Zhan, James (2010) World Investment Report 2010: Investing in a Low-Carbon Economy. S/1: UNCTAD.

Zhu, Xiadong (2012) “Understanding China's Growth: Past, Present, and Future”. Journal of Economic Perspectives, vol. 26, núm 4, 103-124. 